\title{
Techniques and Concepts for Shaping the Future
}

Assessment of Current Planning Thought Through a Content Analysis of Town Planning Textbooks

Lisa Melcher

\section{OpenEdition}

\section{Journals}

Electronic version

URL: http://journals.openedition.org/chinaperspectives/7170

ISSN: 1996-4617

\section{Publisher}

Centre d'étude français sur la Chine contemporaine

\section{Printed version}

Date of publication: 1 March 2017

Number of pages: $7-14$

ISSN: 2070-3449

Electronic reference

Lisa Melcher, "Techniques and Concepts for Shaping the Future », China Perspectives [Online], 2017/1 | 2017, Online since 01 March 2018, connection on 28 October 2019. URL : http:// journals.openedition.org/chinaperspectives/7170 


\title{
Techniques and Concepts
}

\section{for Shaping the Future}

\author{
Assessment of Current Planning Thought Through a Content Analysis of \\ Town Planning Textbooks
}

\begin{abstract}
Which bodies of knowledge and which paradigms of thinking shape spatial plans? A content analysis of three textbooks on town planning shows that on the one hand, planning standards, models, and paradigms for technical modernisation are well developed, while on the other hand, environmental planning and preservation of culture have been identified as current challenges. Introductions to town planning have been found to shift between routinely presenting established approaches and exploring solutions or technical approaches to challenges to town development.
\end{abstract}

KEYWORDS: towns, spatial planning, urban planning, spatial development strategies, urbanisation.

\section{Introduction}

$\mathrm{n}$ cities and towns in China, the visitor often encounters plans or maps of envisaged development and construction for the next 15 years or so. We can find these plans and maps not only in specialised planning exhibitions but also in government-run local museums, or on information boards in the vicinity of local government buildings. They will display colourful renderings of construction areas and development axes, and of land use zoning and grids that structure the town. Invariably, there will also be renderings of what the architecture in these areas is envisaged to look like; the visitor will see big representative architecture, residential high-rises, as well as streetscapes inspired by local traditional architects.

Among the many questions these plans and imaginations raise, from their actual use in policy-making to the background of their production, this paper focuses on one specific detail: the professional knowledge system such plans are based on, and the perception of their tasks and responsibilities by planning professionals themselves. To this end, three recent handbooks on planning small towns are subjected to a qualitative content analysis: (1) Li Jianzhao's (李建到) Manual on the Development and Planning of Small Towns (Xiao chengzhen fazhan yu guihua zhinan 小城镇发展与规 划指南), (2) Luo Zhongzhao's (骆中㻇) et al.'s Planning and Construction Administration for Small Towns (Xiao chengzhen guihua yu jianshe guanli 小 城镇规划与建设管理), (3) and Tang Mingtan (汤铭潭) et al.'s Development and Planning of Small Towns (Xiao chengzhen fazhan yu guihua 小城镇发 展与规划).(4)

Each of these three volumes takes the form of a handbook, explaining contents, regulations, and processes of spatial planning and development to practitioners working specifically in or for small towns. They tackle the technical aspects of planning, such as zoning and construction design, as well as engaging in discussion about which paths of development smal towns can or should choose. The analysis asks which issues are raised to what ends, as well as looking for similarities and differences, so as to gauge the current themes and trajectories of small town planning in China. Areas of consolidated knowledge are identified, along with those that are yet being explored, most notably approaches to environmental protection and cultural heritage.

Before I present the results of the analysis, there will be a short introduction to the status of towns and the literature on planning in China, followed by an overview of the data and my methodology.

\section{Towns and town planning in China}

All three authors connect back to the long-standing debate about the role of towns for development in China. ${ }^{(5)}$ Starting from Fei Xiaotong, ${ }^{(6)}$ there has been support for developing towns and small cities, since they have a high capacity for bringing the rural population into wage jobs, provide trade and services to the countryside, and may ensure a more spatially balanced distribution of wealth. However, throughout the 1990s and much of the 2000s, policies and discourses geared towards strengthening the major cen-

1. The research for this paper has been conducted in the context of a doctoral research project about institutions, paradigms, norms, and ideal visions in spatial planning of towns in Sichuan. I wish to thank the Graduate School for East Asian Studies at Free University Berlin for their generous financial as well as professional support, which is making this endeavor possible. I am also grateful to my PhD supervisors, Prof. Dr. Bettina Gransow and Prof. Dr. Olaf Zenker, both of Freie Universität Berlin.

2. Li Jianzhao, Xiao chengzhen fazhan yu guihua zhinan, (Manual on the Development and Planning of Small Towns), Xin shiqi xiaochengzhen guihua jianshe guanli zhinan congshu, Tianjin, Tianjin daxue chubanshe, 2014.

3. Luo Zhongzhao, Zhang Bo, and Bo Fan, Xiao chengzhen guihua yu jianshe guanli, (Planning and Construction Administration for Small Towns), Xiaochengzhen guihua sheji congshu, Beijing, Huaxue gongye chubanshe, 2012.

4. Tang Mingtan, Song Jingsong, Liu Rengen, and Li Yongjie, Xiao chengzhen fazhan yu guihua, (Development and Planning of Small Towns), second edition, Zhongguo dangdai xiaochengzhen guihua jianshe guanli congshu, Beijing, Zhongguo jianzhu gongye chubanshe, 2012.

5. In terms of towns, the Chinese terminology is not clear. The term usually used is "small cities and towns" (xiao chengzhen) or "medium-sized and small cities and towns" (zhongxiao chengzhen), but there is no common definition.

6. Fei Xiaotong, Small Towns in China. Functions, Problems \& Prospects, Beijing, New World Press, 1986 
tres prevailed. (7) Only more recent Five Year Plans as well as the New Urbanisation Strategy of 2014 have come to advocate balancing the development of large, medium, and small urban centres, with a special focus on development of small cities as regional growth poles. ${ }^{(8)}$ Additionally, the new planning law of 2007 for the first time provides a unified framework for spatial planning in urban and rural areas. ${ }^{(9)}$

The handbooks at the centre of this article have to be read in this context, since for a long time, there was little or no systematic efforts to formulate development concepts for towns. In particular, the attention of spatial planners concentrated on central urban areas, since growth, construction, and investment have been most dynamic there, and they gained the most political attention. This, in combination with other regional policies, has left small towns in China in a rather tight spot: ${ }^{(10)}$ administratively, they are usually below county level. Therefore, resources necessary for policy-making, such as expertise, manpower, or finances, are scarce. In terms of spatial development strategies, local governments have little room to formulate their own policies but are left with implementing higher-level instructions and strategies.

The administrative status is reflected in the physical condition of towns: close to the bottom of the administrative system, they are left with small land quotas and little capital for investment. Accordingly, infrastructure is often weak. Quality of education and healthcare in towns is regarded as lagging far behind that of cities. Moreover, employment opportunities for well-educated people are usually concentrated around the political centres, i.e., in the large cities.

Economically, the situation is not necessarily quite as bleak. As Tang describes, small towns in Southeast China, most notably in Fujian, Jiangsu, and Zhejiang provinces, are regarded as the avant-garde of the economic development of the 1980s and 1990s, whereas in the Northeast, there are still many industrial towns. The Jiangsu and Zhejiang models of economic development basically stand for small-town-centred industrialisation. ${ }^{(11)} \mathrm{Nev}$ ertheless, as can also be seen from the three textbooks, towns are most often regarded as belonging to the rural domain and therefore as backward and lacking in economic opportunity. And even though their residents may have de-facto urban hukou, it does not compare to the right of rural residents to hold land in terms of either social status or social benefit.

The shift in political attention away from large cities, and the position of towns right on the Chinese rural-urban divide, provide the backdrop for the narratives of the three textbooks analysed for this paper. Li and Luo in particular emphasise guidelines on how to apply urban planning to small towns, both for planners (whose experience might be limited to cities) and for local administrators (who previously might have been rather lax about planning). This content in the textbooks is important, since, as Curien demonstrates, top-down regulations and dominant technical approaches have a powerful influence over planning outcomes. ${ }^{(12)}$

Most research about planning in China, however, takes guiding concepts and objectives for granted and instead focuses on planning's position within local growth coalitions. Sometimes, planning is described as an important means of policy legitimisation and place marketing; (13) in other cases, it is presented as merely doing the bidding of politicians and lacking its own "social purpose." (14) Criticism is levelled against the profession mainly for focusing on matters of architecture and design and neglecting other functions planning could take on. ${ }^{(15)}$ Nevertheless, there is general agreement that spatial planning has gained considerable status in place marketing, in managing local development, and in legitimating policy decisions. This article therefore aims to more fully appreciate the knowledge system and logic that planners, as the engineers of spatial development, apply to towns.

\section{Who wrote those books and what for?}

The three books in the focus of the present analysis have been selected on the basis that they are the overview books for the three newest handbook series on planning small towns. ${ }^{(16)}$ The other books in the series invariably focus on specific planning content such as infrastructure, housing, or environment and green spaces, as well as the legal basis for town planning and management and concrete measures for management. In these book series, the respective first authors of the books analysed here also figure prominently as authors of other books; moreover, all three authors also have a great number of other publications on planning and construction. ${ }^{177}$ The research orientations of the three authors are rather diverse. Tang Mingtan has written on small town planning and development for years, whereas previous publications of Luo Zhongzhao have been more in the direction of rural housing construction, including a number of very practical handbooks for people engaged in construction, presenting blueprints. Li Jianzhao has written extensively about infrastructure construction and engineering, with little reference to small towns or rural areas. These differences in expertise are reflected in the content and central messages of the three books analysed.

All three books and book series see practitioners of town planning, administration, and government as their primary audience. Additionally, they seek reception in teaching and studying town planning. The purpose is therefore not the promotion of research or the establishment of new knowledge, but rather the consolidation and communication of established practices and understandings.

Such books are not only reference material for planning students. ${ }^{(18)}$ In my fieldwork, I have also observed planning practitioners regularly consult-

7. Lu Ding, "Evolution of China's Urban Development Strategy and Institutions," in Lu Ding, The Great Urbanization of China, Singapore, World Scientific, 2012, pp. 29-62.

8. Zhonghua renmin gongheguo zhongyang renmin zhengfu (Central Government of the People's Republic of China), "Guojia xinxing chengzhenhua guihua (2014-2020)" (New national urbanisation plan (2014-2020)), http://www.gov.cn/zhengce/2014-03/16/content_2640075.htm (accessed 15 March 2015).

9. Zhonghua renmin gongheguo zhongyang renmin zhengfu (Central Covernment of the People's Republic of China), "Zhonghua renmin gongheguo chengxiang guihuafa" (Regional planning law of the People's Republic of China), http://www.gov.cn/flfg/2007-10/28/content_788494.htm (accessed 15 March 2015).

10. Most of the following insights stem from ethnographic fieldwork on town planning in Sichuan during the year 2016.

11. Tang Mingtan et al., Xiao chengzhen fazhan yu guihua, (Development and Planning of Small Towns), op. cit., pp. 38-78.

12. Rémi Curien, "Chinese Urban Planning: Environmentalising a hyper-functionalist machine?", China Perspectives, No. 3, 2014, pp. 23-31.

13. Daniel B. Abramson, "Urban Planning in China: Continuity and Change: What the Future holds may surprise you," Journal of the American Planning Association, Vol. 72, No. 2, 2006, pp. 197-215; David Bray, "Urban Planning Goes Rural: Conceptualizing the 'New Village'," China Perspectives, No. 3, 2013, pp. 53-62; David Bray, "Masterplanning the nation: Elites and the transformation of China's built environment," in Zang Xiaowei and Kou Chien-Wen, Elites and governance in China, London, Routledge, 2013, pp. 73-93.

14. Michael Leaf and Hou Li, "The 'Third Spring' of Urban Planning in China: The Resurrection of Professional Planning in the Post-Mao Era," China Information, Vol. 20, No. 3, 2006, pp. 553-585.

15. Huang Kuang-ting, Remaking Chinese Planning as a Profession: Growing Demand and Challenges, Ann Arbor, University of Washington, 2012; Michael Leaf, "Modernity Confronts Tradition:The Professional Planner and Local Corporatism in the Rebuilding of China's Cities," in Bishwapriya Sanyal, Comparative Planning Cultures, New York, Routledge, 2005, pp. 91-111; Fulong Wu, Planning for Growth. Urban and regional Planning in China, New York, Routledge, 2015.

16. Being published by China Architecture \& Building Press, the national editing house for architecture and engineering, Tang is probably the most prestigious among the authors cited here. The book and the complete series were first published in the 2000s; many of its books appeared in their second, revised edition between 2012 and 2014. I have not been able to find any other recent book series on town planning.

17. Interestingly, there is no cross-citation at all between the books and authors.

18. The following are preliminary insights from my fieldwork in Sichuan in 2016. 
ing academic material, especially if they were uncertain about how to approach an issue. Moreover, many projects include the consultation of complementary material and case studies of similar projects as references. In those cases, planners would look for ideas and concepts, but also for numerical standards for the allocation of land use as well as the provision of infrastructure.

More generally, there are several conduits through which academic thought, as represented by these books, can influence planning practice and results. Planners usually work outside local government, their main focus of professional engagement being planning laws, standards, and theories rather than concrete localities. The planners I have worked with took great care to stay on top of recent trends and research in the profession, to be informed about and apply new approaches. This is due in part to the fact that their market position depends on their grasp of planning knowledge, and also in part to their status and self-perception as technical experts rather than policy-makers. Many planners simultaneously work in research or education and as practical planners, and many distinguished planning institutes are run by university planning departments. Therefore, there is no clear-cut line separating academic and practical engagement from planmaking.

Moreover, planning at the county or township level has to comply with standards and regulations formulated by higher-level planning departments. People working at universities or doing research on planning usually are consulted in the formulation of such standards and approaches, which is another important conduit for more conceptual thinking into real-life planning and construction.

It is difficult to gauge the extent to which such books are used in the education of planners. In my experience, education is first strongly aligned with the teaching of architecture, and only in later semesters does the curriculum focus on spatial planning, which only recently has begun to include rural space. Teaching at the undergraduate level largely follows the curriculum laid out by Wu Zhiqiang, ${ }^{(19)}$ and there is not much opportunity for specialisation. When studying for a master's degree, students mostly do project work, usually in rural space. At this level, they also are given the chance to choose an area of specialisation. I therefore expect that the impact of specialised planning handbooks, such as the ones discussed in this paper, on regular planning education remains limited.

In overall tone, structure, and approach to planning literature, these three books can be considered representative of wider academic planning publications in China. ${ }^{(20)}$ Discussion typically revolves around how to improve planning through new approaches, techniques, or additional content. The focus is usually on technical aspects of planning. With regard to this body of literature, the three textbooks analysed here have two important commonalities: first, they are rather comprehensive in their content, whereas many other books often look at specific issue areas of planning; second, they share the basic argument that towns and small cities should receive greater attention in spatial development efforts. It is in this latter aspect that the authors take issue with the larger debate, since most planning research and publications focus on big cities or sometimes on the countryside.

\section{Overview of each book}

In terms of structure, content, and arguments, Tang's publication is an outlier. These differences might be attributed in part to the fact that the first version dates back to the early 2000s, although the introduction claims that there have been major revisions. Tang divides the book into two parts of equal length, first presenting general analyses on the role of towns for urbanisation and growth in China, different drivers and trajectories of town development in China, as well as a program for town development and construction. Only the second part of the book deals with town planning specifically. It begins with a presentation of the content, responsibilities, and methods of town planning in general, then argues for improved standards and regulations for town planning before presenting, as a model and example, the planning and development system for central towns of Guangdong Province. A chapter on international theories on small towns concludes each of the two parts. The long appendix provides the current planning law, more technical standards, and exemplary planning maps and pictures.

In contrast to the others, this book relies on the presentation of examples much more than on generalised statements. Much attention is paid to regionally diverse trajectories of development: Tang comparatively analyses models of industrialisation for the regions of the Zhuhai Delta, Jiangnan, Bohai, and Northeast China. Almost all of the many examples cited stem from Jiangnan and the Zhuhai area, clearly where the authors' expertise is drawn from.

The decisive difference, however, lies with the programmatic focus: Tang emphasises systematisation of regulation and standards as well as economic growth and industrialisation, while in the other two books the leading concern is with the creation of an amenable environment and protection of cultural heritage as well as with how to preserve or strengthen the characteristics of each town. Moreover, existing standards for construction are presented in much greater detail and with many more additional models and systematics for planning in those two books.

Luo presents town planning as a branch of rural planning, and many examples and detailed discussions actually stem from rural planning and development. Here, towns are firmly placed in the context of rural development, and one full chapter exclusively deals with village planning. This book dedicates much space to what are described in the abstract and the foreword as the most urgent issues in town development: the construction of local characteristic styles, village development and construction, renovation of old towns, protection and development of historic towns, as well as processes of managing construction in towns. Furthermore, emphasis is given to environmental concerns. It is apparent even from the table of contents that Luo gives cultural and environmental matters much more prominence than the other two books do, and more than is usual in planning literature.

The centre of gravity for Li are the word and spirit of the new urbanisation strategy and the current law on spatial planning. This is reflected in the structure of the book, which like legal texts on planning starts with definitions, proceeds through the hierarchy of plans, and ends with management and implementation. Two aspects are notable in this book: first, for each plan he describes, Li lists in detail which information is needed and where to get it. Second, the book is devoid of examples; instead, it is

19. Wu Zhiqiang, Chengshi guihua yuanli (Principles of Urban Planning), Beijing, Zhongguo jianzhu gongye chubanshe, No. 4, 2010; see also Rémi Curien, "Chinese Urban Planning: Environmentalising a hyper-functionalist machine?", art. cit.

20. This assessment is based on my readings in the China City Planning Review (Chengshi guihua) as well as on engagement with several other planning textbooks. 
characterised by lengthy elaborations on technical standards as well as on systematics and models.

Despite these differences in structure and focus, all three books argue that towns are essential for developing rural areas and for overcoming the twotier system of urban and rural areas; all three books maintain that for these goals, administration and planning of towns have to be strengthened. Moreover, there is a shared understanding that development and construction need to become more "orderly" (youxu 有序) instead of the tendency toward "blind" (mangmu 盲目) activities of the past. In unison and repeatedly, the authors point out the problem of "a thousand towns all look the same" (qian zhen yi mian 千镇一面): they emphasise that attention needs to be paid to environmental and cultural-historical issues to respond to this problem, and claim that it is only through relying on planning that this phenomenon can be mitigated. Each book repeats again and again that planning has to start from local conditions and characteristics, a popular phrase being to "use methods in line with local circumstances" (yin di zhi yi 因地制宜).

\section{Methodology}

My reading of the three textbooks rests on the conviction that there is no objective "right" or "wrong" in planning, but only logics, heuristics, and knowledge systems for understanding the situation on the ground and more or less implicit priorities. Looking at how the authors of those three books present various aspects of town planning, and which aspects they respectively emphasise, I therefore do not aim for a criticism of planning thought, but for a more substantial understanding of the meaning behind maps and renderings. ${ }^{(21)}$

Analysis of the three textbooks was led by the methods of qualitative content analysis and grounded theory and was aided by text analysis software: codes and categories developed inductively during the readings were adjusted repeatedly over the course of analysis. Coding was accompanied by extensive note-taking. While special attention was paid to normative statements in the books, it was of preeminent importance to produce an adequate representation of the issues and foci as they were addressed in the books. (22)

The most voluminous and diverse categories, with more than 300 codings each, hold the specific contents of plans as well as current issues of spatial development in China; both of these categories consist of numerous codes differentiating between various planning contents (e.g., contents of planning documents, regulations to be included in planning, construction planning) and between different issue areas (e.g., land use planning, structural reform, environmental issues) respectively. Also important were concrete technical instructions, elaborations on modes of spatial developments, the history of spatial development in China, and the role towns could and should play. Codings related to the formal planning system also number over a hundred.

Analytical insights were generated from reviewing the notes and the content of codes, thereby creating a more systematic understanding of concepts and knowledge systems beyond the elaborations. This enabled me to compare the different authors' approaches to similar topics and the discussions of different issue areas. It became possible to carve out areas of consolidated knowledge and of academic debate or exploration, and to generate a sense of the normative positions of the different groups of authors with regard to spatial development and planning.

\section{Town planning knowledge: Structures, norms, and explorations}

\section{On the status and development of towns}

Although Luo claims that prospectively, in the course of urbanisation, villages will grow into towns and towns into cities, there is no size-related or numerical definition of towns. ${ }^{(23)}$ In all of the books, towns are defined in functional terms and, most importantly and most widely used, according to their administrative rank: towns are urban-like settlements from the county seat down; therefore, the category includes county seats, townships (xiangzhen 乡镇), other statutory towns (jianzhizhen 建制镇), and market towns (jizhen 集镇). Towns are also defined as the connection between countryside and urban areas; functionally, they are the top level of the rural system and the bottom level of the urban system (cun zhi tou, cheng zhi mao 村之头、诚之毛). ${ }^{(24)}$ This materialises in the fact that they are the political, social, and cultural centres of rural areas, and that they bring urban services such as communication and trade infrastructure and industrial jobs within reachable distance for rural residents. $\left.{ }^{25}\right)$

Li's introduction to what towns actually are starts with their characteristics (small, yet the full set of urban functions; closer to nature than cities, better environmental conditions, and the economic centre for rural areas), discusses the relevance and use of towns (provide a variety of important services for rural development and urbanisation), and then concludes by discussing the spatial distribution of towns. Tang, on the other hand, goes through the various definitions of small towns from various disciplinary perspectives and different countries, before settling on a definition based in administrative rank. ${ }^{(26)}$

The efforts to establish an understanding about the essence, function, and characteristics of small towns stretches to the parts dedicated to planning and development: planning in towns faces different challenges and has to meet other functions than in cities. It moreover is much more encompassing and touches upon a much broader range of issues than planning in cities. (27)

21. However, the reader should be aware that planning thought (especially in its modernist variant, which is dominant in China, see Rémi Curien, "Chinese Urban Planning: Environmentalising a hyper-functionalist machine?", art. cit.; David Bray, "Urban Planning Goes Rural: Conceptualizing the "New Village"," art. cit.) always tends to homogenise space by overlaying the landscape with abstract large-scale models.

22. Although inductive qualitative text analysis aims at the greatest possible impartiality, the perspective is necessarily influenced by the author's own views and interests. The motivation for my research is the conviction that spatial development focusing on towns is, for a variety of reasons, to be preferred to spatial polarisation between huge cities and the countryside. I share this view, if not all arguments supporting it, with the authors of the books analysed. Moreover, since the larger research context looks at the paradigms, systems of knowledge, and values with which planning and planners operate, my focus was tilted towards those aspects rather than to more technical or legal content.

23. Luo Zhongzhao et al., Xiao chengzhen guihua yu jianshe guanli, (Planning and Construction Administration for Small Towns), op. cit., p. 3.

24. E.g. Li Jianzhao, Xiao chengzhen fazhan yu guihua zhinan, (Manual on the Development and Planning of Small Towns), op. cit., p. 1; Tang Mingtan et al., Xiao chengzhen fazhan yu guihua, (Development and Planning of Small Towns), op. cit., p. 26.

25. E.g. Li Jianzhao, Xiao chengzhen fazhan yu guihua zhinan, (Manual on the Development and Planning of Small Towns), op. cit., p. 3f, Luo Zhongzhao et al., Xiao chengzhen guihua yu jianshe guanli, (Planning and Construction Administration for Small Towns), op. cit., p. 11; Tang Mingtan et al., Xiao chengzhen fazhan yu guihua, (Development and Planning of Small Towns), op. cit., p. 24 and 27.

26. Li Jianzhao, Xiao chengzhen fazhan yu guihua zhinan, (Manual on the Development and Planning of Small Towns), op. cit., pp. 1-3; Tang Mingtan et al., Xiao chengzhen fazhan yu guihua, (Development and Planning of Small Towns), op. cit., pp. $8 f$.

27. Li Jianzhao, Xiao chengzhen fazhan yu guihua zhinan, (Manual on the Development and Planning of Small Towns), op. cit., p. 178 and 277; Luo Zhongzhao et al., Xiao chengzhen guihua yu jianshe guanli, (Planning and Construction Administration for Small Towns), op. cit., pp. $14 f$. 
The desire to impress on the reader that towns are a fully-fledged spatial category, and that they merit specific approaches in planning and policymaking, is common to all three sets of authors.

All authors emphasise that towns are closely interconnected with their regions and thus diverse in their histories and specialisations. Various categorisations of towns are offered:Tang bases his entire presentation and analysis on a differentiation between various organisational models of economic growth: the foreign investment-based industrialisation in the Zhuhai area, the development of locally-based small industries in the Sunan region, and the absence of a clear model in the Bohai region. Tang also provides a whole range of other options for categorising towns, most importantly: by physical geographical location, by their functional specialisation (e.g. comprehensive towns, social services, transport nodes, economic and industrial centres, etc.) or by their position in the regional context, i.e., whether they are satellites to large cities, parts of town clusters and urbanised areas, or centres of agricultural areas. Later on, a typology by sources of capital and investment for economic growth is presented. (28) Li instead lists categories for describing the attributes of a town: physical geography, core functions, location relative to other settlements and infrastructure, as well as the major source of investment capital; for each category, different options are provided. He furthermore sees the status of the towns within the regional context as defining the "character" (xingzhi 性质) of a town; yet character is not necessarily a given but something that is to be analysed, determined, and realised by and through planning. ${ }^{(29)}$ Luo finally provides a detailed economic typology of towns, starting with towns providing administrative functions, through specialisation in agricultural industry or trading (in different variants), down to historic and cultural towns. ${ }^{(30)}$ Such typologies serve to make the case, repeated throughout the three books, that plans and development strategies have to be based on actual local conditions and on a thorough understanding of specific circumstances. In my research, I have found these to be necessary interventions, since there was little conceptualisation and understanding of the diversity of towns and the resulting necessity for adjusted development concepts among politicians, and to a certain degree also among planners.

Although the histories the three books tell about the role and development of towns in China vary considerably, ${ }^{(31)}$ all authors call for strengthening towns with a favourable basis for future development. Industry, infrastructure, public services, as well as economic opportunities in each county are to be concentrated in three or four central towns. Their population is to grow through absorbing workers from the surrounding countryside. The arguments for this are that there are currently too many towns in China, and most of them are too small. Through focusing development on central towns, cover with social facilities and infrastructure is to be extended and robust growth poles are to be created in an effort to reduce migration pressure on the large agglomerations. ${ }^{32)}$

It is notable how the authors pursue rather different routes in the systematisation of knowledge, whereas their normative points and conclusions are perfectly synchronous. Many of their points can be found in recent documents and regulation about planning; the strategy of developing central towns, for example, is one of the pillars of the new urbanisation strategy.

\section{Structures: Accounts of the planning system}

After arguing that planning is indispensable for ordered development, presentations of planning and the planning system start with the general plans for a county and for a town, then go on to issue-specific and construction planning, and then last but not least to looking at management and implementation. Differences mostly lie in what is presented before and in between those explanations.

Li's presentation of the general plan focuses on land use planning and recommends including separate maps for the various land use categories (residential, industry, public facilities including commerce, and a construction land use plan). Standards for infrastructure, such as internal roads or storage facilities, are provided, and short-term construction planning is discussed: Li gives guidelines on how to prioritise, and on which decisions need to be taken. Chapter Five looks at legally-prescribed issue-specific plans, namely the various infrastructure networks, disaster prevention and risk reduction, natural environment, as well as history and culture planning. In a very similar fashion, Chapter Six presents construction plans (here: xiangxi guihua 详细 规划) for a variety of issue areas: residential areas, town centre and commercial spaces, green space and public squares, industrial parks, how to deal with old towns, and finally "vertical planning" (shuxiang guihua 竖向规划), i.e., the detailed design and standardisation of ground levels between streets and buildings of different functions. For each respective plan, Li lists the issues it is supposed to solve, the principles, rationales, as well as central techniques, models, and legal standards. He usually gives a few tips about which aspects to pay special attention to and what would characterise a good plan. Yet, the only aspect to be consistently dealt with in detail is the list of materials and information to be collected in preparation for plan-making an aspect that is mentioned only briefly in an overview chapter by Luo and not at all by Tang. Overall, these presentations are more than specific enough to understand what is going on in a planning process, but not quite enough to be a practical manual for plan-making.

This structure and logic of presenting the planning system is significant because many of its elements are rather similar in Luo and Tang. Luo interrupts this structure with a chapter on the outer appearance and protection of environment as well as historic styles; issue-specific plans and construction plans are dealt with in one chapter without differentiation. Yet, the form of presenting standards and models is strikingly familiar to Li. Tang, however, is rather brief in introducing the formal planning system, and large portions of the legally binding standards are relegated to the appendix. He concentrates on recommending specific approaches for various kinds of towns, depending on their location relative to other settlements, as well as arguing for improving the system of standards by presenting the guidelines and standards for planning central towns of Guangdong Province, emphasising the concepts, systematics, and standards that are to guide plan-making. This last presentation, again, exactly follows the structure and choreography of Li's presentation of the overall planning system. There

28. Tang Mingtan et al., Xiao chengzhen fazhan yu guihua, (Development and Planning of Small Towns), op. cit., pp. 11-14, 43-46.

29. Li Jianzhao, Xiao chengzhen fazhan yu guihua zhinan, (Manual on the Development and Planning of Small Towns), op. cit., pp. 4 ff.

30. Luo Zhongzhao et al., Xiao chengzhen guihua yu jianshe guanli, (Planning and Construction Administration for Small Towns), op. cit., pp. $11 f$.

31. Notably, though, none of these histories has anything in common with the histories of urban development in China usually told in the background chapters of research on cities and urban planning.

32. E.g. Li Jianzhao, Xiao chengzhen fazhan yu guihua zhinan, (Manual on the Development and Planning of Small Towns), op. cit., preface and pp. 43-51, 255f, 277; Luo Zhongzhao et al., Xiao chengzhen guihua yu jianshe guanli, (Planning and Construction Administration for Small Towns), op. cit., p. 4, chapters 2 and 5; Tang Mingtan et al., Xiao chengzhen fazhan yu guihua, (Development and Planning of Small Towns), op. cit., pp. 20f, 26-36. 
clearly is a common heuristic and routine to identifying and describing a planning framework.

There are only limited descriptions of the concrete workflows of planning Luo provides one overview: collect the material, decide on the levels in the system and the general trajectory of future development, and then produce the plan. ${ }^{(33)} \mathrm{Li}$ includes very similar steps in plan preparation for various specific plans, most comprehensively for the renovation and extension of old neighbourhoods and towns. He begins these lists either with the collection of material or with the concrete formulation of the issues to be addressed in the plan, and invariably concludes with the documents to be included in the plan: the maps, the legal text of the plan (wenjian 文件), and the explicatory description (shuomingshu 说明书). In their brevity and their focus on preparations and results, these explanations are clearly addressed to actors in local administrations and governments, since the process of planformulation, which would be of interest to planners, is barely elaborated.

In both Li's and Luo's books, the last chapter is dedicated to management and administration. Li elaborates on "planning control," i.e., the procedures of control and permission in construction control as well as mechanisms to ensure the quality of a given plan and the buildings themselves. He even gives recommendations on the formulation of construction and planning contracts. Also considered are the procedures for changing the plan in light of new circumstances or developments. Tang's explication of the Guangdong planning standards for central towns in Chapter Seven dedicates one of three subsections to management and control. The legally relevant aspects are therefore covered in each book.

Nevertheless, it is mostly organisational issues that are conspicuously absent from these presentations of the planning system: nowhere is it discussed how planning is to fit in with the policies of other departments, or how to communicate the contents of planning to those departments that might be expected to be directly involved in implementation, such as the departments for environmental protection or culture. Also, there is no discussion of how to practically organise the cooperation between planning institutes (which, by law, are the organisations creating the plan) and the government. Therefore, although the authors are at pains to emphasise that plan-making has to be guided by the characteristics and empirical situations of the towns and regions themselves, they neglect to locate planning within a political system and position it in relation to other administrative jurisdictions.

These blind spots in regard to the more coordinative and perhaps political role of planning are once again common to all three books. And although Tang's approach is more explorative and much more bent on arguing for reform and innovation of the planning system, the authors clearly share an understanding of which aspects of the planning system have to be explicated and included, how to present the planning system, and the tasks and objectives of planning. The power of these approaches can be seen clearly in real-life zoning plans for small towns: land use functions are assigned according to well-practiced routines and prescribed standards, often with little regard to existing construction; and in infrastructure planning, there is often no elaboration or discussion, since the approaches are treated as self-evident. In these respects, I argue, there is a unified, taken-for-granted understanding of the planning system; planning is seen as a simple application of standards and regulations. That these techniques receive so much attention in the books, however, points to a perceived need to support planners in enforcing the standards and to offer condensed compilations of the material relevant specifically for small towns.

\section{Norms and values: Where and how to develop?}

The authors agree in emphasising the role planning plays in harmonising different aspects of town construction and development to form a coherent whole. Criticisms of the planning profession and practiced development policies however vary with their individual academic backgrounds.

Luo's central concerns with regard to urbanisation and development reflect the needs and perspectives of rural residents - resource consumption by cities, the loss of agricultural land and the rights of rural population to just compensation, as well as the integration of new urban citizens. He also argues for a valuation of local and everyday culture, and for not pursuing a unified picture of urban modernity everywhere. ${ }^{(34)}$

Luo's first two chapters call for a strategic outlook and long-term development perspectives, for mindfulness of local social, economic, and environmental conditions and needs, and for clearly stating the direction and foci of development so that construction and policies can proceed in a coordinated way. He criticises an overemphasis on construction of buildings and housing at the cost of infrastructure and environment, and thinking that favours short-term and area gains to the neglect of long-term strategies and quality of construction and growth. These statements are rather subtly woven into the text, yet in their overall tone and content, they can easily be read as a critique of current planning practice or the lack of effective planning and control. (35)

Li criticises similar issues, but from a more technical point of view. He takes issue with unordered processes and outcomes of construction as well as with the lack of infrastructure and environmental protection. His answers to these problems, accordingly, lie with scientific and rational approaches, strengthened management, as well as increased investment in infrastructure. In this vein, and in the explication of each type of plan and content of planning, Li lists the principles that have to be observed to create a good plan, which vary widely between types of plans. For example, the principles for designing the infrastructure network for natural gas supply state that the general plan has to be followed and at the same time, the energy situation of the larger region has to be considered. Short and long-term should be coordinated. Policies should be designed for the short term, but they have to consider future options for expansion; the temporal limitation of the plan should be set in accordance with the national economic plan. Furthermore, the plan has to meet the requirements of taking into account the full complex set of factors, of being comprehensive in its arrangements, adequate to local conditions, and protective of the environment. ${ }^{(36)}$ Following this, Li first lists the objectives and tasks of planning a network for natural gas before going into each of the contents of this specific plan.

This is one example of many, and it shows how intent Li is on technical perfection and quality of planning. He emphasises detail and the individual plan, where Luo looks at coordination and integration. Tang's position visà-vis planning practice takes a much more system-oriented perspective. He finds very clear words to criticise planning that has degenerated into pandering to politicians' career calculations instead of serving long-term de-

33. Luo Zhongzhao et al., Xiao chengzhen guihua yu jianshe guanli, (Planning and Construction Administration for Small Towns), op. cit., pp. $40 f$.

34. Luo Zhongzhao et al., Xiao chengzhen guihua yu jianshe guanli, (Planning and Construction Administration for Small Towns), op. cit., pp. 8-10, 76-78.

35. Ibid., pp. 5ff, $41,45,79$

36. Li Jianzhao, Xiao chengzhen fazhan yu guihua zhinan, (Manual on the Development and Planning of Small Towns), op. cit., pp. 34ff, $156 \mathrm{ff}$. 
velopment. Tang presents two lists of problems, their root causes, and suggestions for solving them, one list in the context of town construction and the other as part of the general introduction to planning. ${ }^{(37)}$ In their core content, both lists are rather similar: towns are too small, do not exhibit enough centrality, construction is chaotic, there is waste of land and environmental pollution. Moreover, all towns look the same, and there is little specialisation or coordination. These problems echo the diagnosis Li gives, yet they are complemented by structural root causes or suggestions for structural reforms respectively: apart from the cited criticism of the attitude of planners, Tang cites the structural separation between urban and rural areas, lack of funding, and a lack of regional cooperation. Besides designating central towns, reforming administrative areas, and strengthening administration and control, he recommends disseminating models for the preservation of local styles and reform of planning procedures and content so as to strengthen control and limitation of land use. Much of Tang's Part Two reads like a political program, citing suggestions, recommendations, and positive examples rather than discussing the current system.

Despite these different lines of argument, a common direction can be seen: all authors suggest a turn towards local heritage and local characteristics as a solution to uniformity; moreover, they criticise generic, poorlyresearched plans in areas ranging from infrastructure construction to economic development. (38) These calls fall on fertile ground, as can be seen not only in the growing role planning plays in town construction, but also in manifold cultural and tourism development projects in many small towns. In this implementation, however, a new generic approach to development seems to be emerging.

\section{Explorations: Environmental and cultural planning}

In principle, all authors agree that planning has to contribute to the protection of the environment as well as to the preservation of local characteristics (difang tese 地方特色). In Li and Luo, the protection of environment and cultural heritage far outranks all other planning issues. ${ }^{(39)}$

$\mathrm{Li}$ argues that pollution and environmental degradation are among the central problems towns are facing. ${ }^{(40)}$ Planning of green spaces and issues of environmental protection as well as preservation of historically valuable structures alike are covered in depth in the chapter on issue-specific planning, but come up in other sections of the book as well. These passages stand out since they pay much attention to the principles, problems, and causes that are the backdrop to preparing these plans and argue their relevance. There is specific discussion about administrative issues and possible conflicts, and more examples are given than in the rest of this book. ${ }^{(41)}$ Environment and culture are perceptibly treated in a more exploratory and conceptual fashion, the focus being less on technical details and standards and lying much more with the question of how to think about these matters and why they are important. However, especially in the chapter on environment, approaches sound unrealistically advanced and unfeasible.

This special treatment of environmental and cultural issues is even more pronounced in Luo: two whole chapters and sections of the chapters on construction and village planning are dedicated to creating amenable landscapes and protecting traditional appearances. There, Luo argues for a holistic approach that preserves or tries to recreate harmony between human settlements and the environment; plans therefore have to be based on an understanding not only of traditional spatial layouts but also of local values and non-material culture. Luo also includes lists of very specific measures, from fire safety through concrete construction limitations within protection zones to relieving high population densities. Neither the content nor the approaches and measures that Luo proposes in these sections are covered in a similar way in any of the other books. In fact, although both Li and Luo do pay exceptional attention to matters of environment and culture, their approaches, discussions, and theories are far apart. Tang, however, stands even further apart, since his strategic considerations look to economic factors and industrial development instead of culture, environment, and style. ${ }^{(42)}$

Environment and culture as issues in planning are conceptualised in rather varying ways, their presentation explorative and argumentative. There is a discrepancy between the rather routine presentation of established planning content on the one hand and argumentative, conceptual, and theorising discussions of environment and planning on the other. The framing and addressing of these issues are still very open, since these sections contribute to planning discourse and the dissemination of new techniques. The information is based on projects in which the authors have participated themselves, presumably experimental or model projects. These issues are very high on the agenda in current planning discourse and practice. In my experience, many towns now invest in the protection of historic buildings and locally themed streetscapes, but I have never seen substantial interest in environmental issues. Overall, since planning projects in small towns and rural areas often suffer from time pressure and poor funding, it is not to be expected that the approaches suggested will be applied in full.

\section{Conclusion}

The three textbooks address the content and issues of town planning as technical problems: their presentations clearly suggest that well-done planning can resolve problems such as "all towns looking the same" or unordered and blind development. They moreover actively explore approaches to address concerns about living environment and loss of cultural heritage in planning. It is clear that the authors aim not only at explaining but also at changing planning.

The authors emphasise that plans have to fit local characteristics and that plan-making has to be based on thorough data analysis; they propose concepts for thinking about local development, environment, and culture. All of these issues are addressed in a language of technical instruction, rather than of academic discourse or social debate. However, there is no conceptualisation or even recognition of administrative and social complexities in

37. Tang Mingtan et al., Xiao chengzhen fazhan yu guihua, (Development and Planning of Small Towns), op. cit., pp. 91-96, 153-160.

38. Li Jianzhao, Xiao chengzhen fazhan yu guihua zhinan, (Manual on the Development and Planning of Small Towns), op. cit., pp. 60-63 and in every instance of explaining which material to consider for any given plan; Luo Zhongzhao et al., Xiao chengzhen guihua yu jianshe guanli, (Planning and Construction Administration for Small Towns), op. cit., pp. 37,45,68, 108; Tang Mingtan et al., Xiao chengzhen fazhan yu guihua, (Development and Planning of Small Towns), op. cit., pp. 100, 136, 164-166, $194 f$

39. These are indeed rather new issue areas, as Yu Li explains for environmental planning:Yu Li, Chinese City and Regional Planning Systems, Farnham (Surrey), Ashgate, 2014. Huang has written a wellcited monography arguing for integrating cultural aspects into planning, claiming that this issue had not yet received systematic attention: Huang Kuang-ting, Remaking Chinese Planning as a Profession: Growing Demand and Challenges, op. cit.

40. Li Jianzhao, Xiao chengzhen fazhan yu guihua zhinan, (Manual on the Development and Planning of Small Towns), op. cit., pp. 35, 47f, 177-203, 204-220, $265 f$.

41. From changes in writing styles I assume, moreover, that both chapters have been written by people other than the main author.

42. E.g. Tang Mingtan et al., Xiao chengzhen fazhan yu guihua, (Development and Planning of Small Towns), op. cit., pp. 31-67, 160-166. 
plan-making: the representations of newer issue areas such as environment and cultural heritage touch upon the domains of environmental and cultural departments, but these overlaps are not mentioned at all. The persons or social groups who are to live in the towns, and who tend to be messier and more complicated than infrastructure and construction blueprints, do not seem to be present in the textbooks. Also, if planning implementation is discussed at all, it is done in a very schematic way, with little attention to concrete workflows and issues.

The attention given to technical detail demonstrates the dominance of theory-led thinking in planning, which has been criticised by much of the research on spatial planning in China. Yet, the technical standards allotted so much space are legally binding. In these passages, the textbooks act as reference works for planning practitioners and administrators, while making a strong argument to the politicians among their readership about the relevance and power of the legal framework.

In the more argumentative sections, the books concern themselves with problems in town planning, most notably generic planning that ignores local characteristics, as well as issues with living environments and preser- vation of cultural heritage. While they suggest working techniques for planners to avoid these problems, the authors neglect to mention that the root causes of these issues lie in the administrative and planning system: planning projects usually take place under time pressure and are poorly funded, not allowing the time and effort required to scrutinise local characteristics. Moreover, implementation depends fully on political will - if a plan does not fit the political priorities of the moment, a new plan will be drawn up. Therefore, realisation of the ideas and experiences depicted in the textbooks relies on the goodwill of political leaders more than on technical expertise.

Lisa Melcher is a PhD candidate at the Graduate School of East Asian Studies of Freie Universität Berlin.

Freie Universität Berlin, Hittorfstr. 18, 14195 Berlin, Germany (Imelcher@gmx.net).

Manuscript received on 1 June 2016. Accepted on 15 December 2016. 